\title{
A 'fair innings' for efficiency in health services?
}

Nick Bosanquet Imperial College School of Medicine, University of London

\begin{abstract}
This paper reviews the severe visual focus problems of health economists-they have developed a one-sided fixation with equity issues, neglecting the efficiency agenda. The problems of meeting need are not just about access-they will vary with cost and supply. Economists in fact developed a more balanced agenda in the 1970s but have failed to follow it up. The paper defines the triple nationalisation of the National Health Service (NHS), and presents evidence that pluralism, using the purchaser/provider split, has become more efficient in long term care, home care and services for people with learning difficulties. Health economics has failed to explore options for using the dynamic forces of choice and competition for improving health services. The paper makes the case for a decision rule that "we should seek the process of health care service supply and development which maximises the delivery of high quality, lower cost user relevant services".

(Fournal of Medical Ethics 2001;27:228-233)
\end{abstract}

Keywords: Health economics; equity; efficiency; "need"; National Health Service; choice

The term "need" has been naturalised into discussion of economic problems of health services without gaining full citizenship as an economic concept. Use of the term has established some common ground between health economics and social policy research but it has also had a critical influence on the direction and focus of health economics itself. By shifting attention to the demand issue of access to services, it has blocked off a whole supply-side agenda about the actual performance of health services. Economists have spent far more time on issues of distribution of health services or access to health services than on those of efficient production. Little has been said on the issues of whether to use the forces of choice, competition and innovation to drive forward improvements in health care. Economists have been more concerned about threats to equity than about whether the NHS process could develop a sustained momentum towards better outcomes. My aim in this paper is to review how the agenda came to be so abbreviated and to set out some alternatives.

Health economics in the UK has become mainly a system of measurement. Its main work has been on techniques of measuring and assessing need through the use of the Quality Adjusted Life Year
(QALY) and other measures within the existing pattern of services. It has contributed rather little either to the management task of using limited resources to improve results or to the policy challenge of using incentives to reduce social costs. In effect health economists have come to provide an essential element of support for the existing state monopoly in the UK. The case for tax funding of health services has had far more attention than the case against monopoly. ${ }^{1}$ They have concentrated on the ethical status of intentions rather than on the measured results. The NHS may well be a noble aspiration yet it needs to be judged by results. The moral priority of achieving results means that we are failing unless we search as intensively as possible for better solutions. Absorbed by the problems of philosophy and measurement of need, effectiveness and equity economists have failed to define options for improving the efficiency and performance of the health care delivery process in any sustained or vigorous way.

The concept of need has had an unusual political and cultural history. Before 1945 it was a term used mainly by supporters of limits on state activity. Need implied moral worth: the Charity Organisation Society stressed that dependency should be minimised by careful examination of the support required to help people to independent living, an early form of welfare to work. ${ }^{2}$

The Beveridge report marked the beginning of the shift towards the later usage of "need" as a term for insufficient access to services by groups. The report used "need" in the sense of social contingency due to chance, economic misfortune or the life-cycle. There were eight primary causes of need, such as unemployment and retirement, which were "so general and so uniform as to be clearly fit subjects for voluntary insurance". Need was created by social circumstances beyond the control of the individual. It was not a matter of identifying moral worth in an individual. Dedicated administrators could fashion programmes to meet need across whole groups in population without any test of individual worth. ${ }^{3}$

By the 1970 s, "need" was used mainly to measure inadequate access to services rather than income. One of the most widely used definitions was that of Bradshaw:

"Normative need is that which the expert or professional, administrator or social scientist defines as need in any given situation. A 'desirable' standard is laid down. Felt need is equated with 
want. When assessing the need for a service, the population is asked whether they feel they need it. Expressed need or demand is felt need turned into action. ... Comparative need is obtained by studying the characteristics of the population in receipt of a service. If there are people with similar characteristics not in receipt of a service then they are in need."

This definition has helped to create a great deal of literature on inadequacy of access. There was much less attention, however, to the implications for supply. The degree of exclusion and non-receipt of a service will depend on the supply available. If the service is "cheap" then access is likely to be much easier. The size of the gap in need will depend on the nature and supply of the services. For high-cost complex services the gap is likely to be very largefor others it is likely to be much smaller and with a limited total budget, a higher unit cost of a service will limit its availability. The extent of need will be deeply influenced not just by the assessment of the experts but by the supply side of the welfare economy.

\section{Influential definition}

Matthew gave another influential definition in the early 1970 s which was more directly related to health services: "A need for medical care exists when an individual has an illness or disability for which there is an effective and acceptable treatment or cure". ${ }^{5}$ Even in this simple definition, however, there is a hidden supply implication. In practice the access to these effective treatments will depend on their cost. Unless there is unlimited funding the available budget will only buy a certain number of effective treatments and their unit cost and total volume will help to set the degree of rationing.

The 1970s also saw an increasing interest in the concept of need on the part of health economists, for example in contributions by Culyer $^{5}$ and Williams. ${ }^{6}$ At this stage they regarded the concept of need with a great deal of suspicion. The agenda as set out by Culyer covered supply as well as the demand issues of measuring inadequacy of access.

How can we measure the costs as well as the effectiveness of different programmes? The need for care will be variable over time and will be influenced both by changing perceptions and by changing costs. The special contribution of health economics was in fact seen as being in this area. "The particular contribution that economics can make, however, derives from the proposition that the degree to which any given need will be met will also depend on the costs of meeting it." "

How are needs to be ranked and what trade-offs are to be allowed between different needs? The effects of differences in costs were stressed. How will the capacity of the system to meet need be influenced by its relative availability and cost of services? "We are forced to rank needs, to assess and to reassess priorities as resource availability changes through economic growth or decline or as the relative cost of meeting needs changes for technical reasons." ${ }^{7}$ Here an agenda is defined so as to cover supply as well as equity issues.

How much progress has been made on this research agenda since the 1970s? The issues of equity have had almost exclusive attention. The Culyer agenda of the 1970s pointed forward towards a programme that would have involved research both on equity and on efficiency issues. In practice it is the measurement of cost-effectiveness that has been the main focus for health economists. They have set up techniques of measurement-but they have done much less on defining methods on the supply side by which it might be possible to increase effectiveness. Among the key developments have been:

The birth of the QALY and its widespread use in comparing cost-effectiveness across health programmes. This concept, developed in UK health economics, has, along with later variants such as the DALY, (Disability Adjusted Life Years) had a worldwide impact.

The distinction between personal and social choice in deciding on which programmes to adopt. The heaviest burden of responsibility falls on policymakers, whose unenviable task is to detect and clarify and to give operational content to the wishes of society.

The varying definitions of equity and the issue of whether equity requires equity of utilisation or of access. ${ }^{8-11}$

All these issues have been well discussed and there is no doubt about the net outcome of the debate in terms of a priority for policy-makers. It has been to increase the emphasis on the reasons for rationing services. There has certainly been a big expansion of the use of cost-effectiveness techniques: but health economists have mainly set out to observe and classify. They have spent much less time and effort on searching out ways to increase cost effectiveness. There are some hopeful signs as the National Institute for Excellence (NICE) begins to develop more guidelines and protocols for actually using therapies more effectively and there is the development of national service frameworks ${ }^{12}$ but this is still only a small beginning.

\section{Lowering costs}

There has also been rather little research on ways of raising efficiency and lowering costs in health services. These are taken as given and the rationing decisions are then made according to the costs and "prices" presented from the medical "deus ex machina". There seems to have been little concern with the potential for reducing opportunity cost through lower costs and prices: yet while such decisions might not eliminate rationing they might reduce it. In effect health economics has concerned itself with rationing, assuming that the health production system is highly efficient. It has not charted the possible losses from monopoly: nor has it charted the gains from allowing more choice. 
The degree of efficiency and flexibility in a service will affect the extent and type of rationing which has to be faced. Even if health services were operating in a highly efficient manner, there would be some rationing as a result of the high cost and scarcity of certain types of service such as heart, liver or kidney transplants. It is important, however, to distinguish such "intrinsic" rationing from the rationing which is caused by supply limitations arising from monopoly. ${ }^{13}$ The social losses arising from rationing will be increased by such supply limitations: and there will be further losses if there is little role for "consumer" preferences in deciding on the pattern and type of services to be provided. A monopoly may in fact be in the paradoxical position of rationing services of a type the "customers" would not choose for themselves. There may be a double loss of having to wait for the service and then not getting the service they actually want.

\section{Decision rule}

What are the key supply hypotheses that might lead to altered perspectives of need-the areas of the Culyer 1976 agenda that have mysteriously dropped off the end of the health economists' world? Can we define the missing research agenda on these efficiency issues? There might be a fairly wide consensus in support of a decision rule that we should seek the process of health care service supply and development which maximises the delivery of high quality, lower cost, user relevant services. This decision rule would allow concentration on those areas of service where there might be gains to new incentives rather than on those where rationing was always going to be likely for intrinsic reasons: it might seem that such a decision rule is too much in the apple pie category. In fact it points towards a very challenging research programme on a range of issues which are far from simple.

Health services in the UK are delivered by a public monopoly. One key issue for the supply-side agenda is that of the possible losses from this monopoly. The older textbook case concentrated on the impact of monopoly in leading to higher prices and lower output but recent advances in economics have added more dimensions to this critique of monopoly. A centralised monopoly will have problems in acquiring accurate information about events at the local level. There will tend to be a gap between the lofty aspirations at the centre and the day-to-day realities at the local level. Monopoly will not generate the pressure to innovate that arises when there is a cluster of competing firms. ${ }^{14}$ Monopoly will have opportunity costs in the loss of new services and products that might have resulted from greater pressure to innovate. Monopoly will be more open to producer capture: the bestinformed people in the system will be the producers who will wield the most power. Finally monopoly may create a higher risk of systems failure. These possible problems with monopoly surely deserve more consideration than they have received from health economists. The case against monopoly is much wider and stronger than it was two decades ago. Monopoly does not simply raise price and lower output. It has fundamental effects on the range of output and on incentives for innovation, and the effect of national monopoly in cramping access to capital and reducing information in a more open international economy needs also to be taken into account.

The particular form which monopoly takes in the UK is that of triple nationalisation of health services. Funding is nationalised and so are resource allocation and the provision of services. This surely points to an agenda of research on the practical effects of such triple nationalisation. Locally, the NHS in effect faces three major tasks, each involving different kinds of risk. Firstly, there are the problems of managing public sector budgets so as to avoid overspending on annual budgets. Secondly, there are problems of allocating funding for local programmes in face of political and professional disagreements. Decision making can be extremely slow with much staff time wasted and decisions on suboptimal facilities can be postponed for years. Health services are not the scene of an active or relentless drive to secure value for money; rather they are the scene of bargaining between professional interest groups about change, which often seems interminable. The system generates little sense of personal responsibility for the efficient use of funds. Thirdly, managers of health services have the job of organising and providing services. They do this as part of a large organisation and they have to use particular approaches involving professional development over the whole lifespan. The old public sector style of organisation may have strengths in certain situations, but it is a very difficult system for getting quick results. Again there are a huge number of supply-side issues which have been ignored and which have become more important as the range of programmes delivered by the NHS has enlarged since the 1970s.

\section{Different priorities}

Health managers thus face a bewildering array of different priorities. They have to ensure that they stay within budgets, where there are many different subprogrammes, each with its own scope for unexpected developments or overspends. They have to establish a consensus about changes in service patterns, meeting political demands from above as well as the interests and concerns of local communities and patient groups. They have to ensure that the services are staffed and provided to consistent quality. These multiple and unpredictable concerns must lead to severe problems in developing programmes and reduce specialisation in carrying out tasks. In effect managers have to develop expertise across three widely different areas. This production system would only be the one of choice where a very slow pace of change was acceptable.

A purchaser/provider split can lead to more effective use of resources and speedier decision making. It has in effect been a way of reducing the triple nationalisation of health services so that there 
can be specialisation in funding and strategic decisions about resources by the funders while the providers can manage services. The conceptual arguments for such a system seem overwhelming and the practical evidence highly positive. Yet health economists in the UK have, with some exceptions, had rather little to say either about the conceptual advantages of the purchaser/provider spilt or the practical gains from the policy which have appeared in practice. It has been left to the World Health Organization (WHO) to make the case for stewardship a government responsibility, and to promote positive health provision across the whole of society rather than across a narrowly defined public sector..$^{15}$ It has also been left to the WHO to advance the hypothesis that the development of the purchaser/provider split through contractual relationships could be a positive force for improving health services. ${ }^{16}$

Health services can be improved through the use of pluralism, the use of public funding to develop long term contracts, and partnerships for supply with a variety of organisations, including profitmaking firms and voluntary organisations. The case for pluralism starts from the actual experience with services that have adapted this model. The evidence shows that the model has worked well in developing services for deprived groups of patients.

\section{Services for people with learning difficulties}

The NHS inherited about 50 large "subnormality" hospitals/institutions from local government. There was little improvement in conditions over the first 25 years until a series of scandals and inquiries in the late $1960 \mathrm{~s}$ led to greater demand for reform. ${ }^{17}$ However, it was to be some ten years before there was much progress towards new models of care.

These new approaches were based on social models of care or a philosophy of normalisation which were almost entirely drawn from US rather than UK experience: people were to live as normal citizens in a community setting. Staff developed strong, caring relationships with patients and helped them with day-to-day living. They also organised activity programmes at local colleges where possible.

These services are a major challenge to organise. They involve partnership with housing associations, winning support from local residents and motivating staff to take responsibility on a 24 -hour basis. But the programme has been highly successful in creating a range of opportunities for people, even where learning difficulties were great. New staff groups have developed, with skills based on social rather than medical models. The services that are available are now much better than they were, but it is highly unlikely that the NHS could have made as much progress if it had remained the direct and sole provider. ${ }^{18}$ In this field, residential care purchased from the independent sector now amounts to $62.3 \%$ of NHS expenditure. ${ }^{19}$

Pluralism was able to offer greater flexibility. The NHS would have had great difficulty in moving from a medical to a social model. Finally, there were gains to specialisation. Many of the organisations involved were committed to this one activity. They needed to carry through projects and they had the specialisation and incentive to do so. In fact they were working to a double incentive of meeting contracts and facing professional scrutiny from within the NHS and social services. Even by the 1980s private and voluntary providers were offering placements of acceptable quality at costs below those of hospitals. ${ }^{20}$

\section{Services in long term care}

There has been much debate on how far the continuing care of elderly people should be a responsibility of the NHS. There has been much less debate on the continuing and fundamental problems which the NHS has faced in actually providing such care. After Townsend's survey of 1960 there was little progress for the following two decades in finding better solutions. ${ }^{21}$ Indeed, the poignant testimony of a relative in Sans Everything in the late 1960s, was still being echoed as late as 2001 in the recent Report of the Standing Nursing Advisory Committee. ${ }^{22}$

Since 1979 private nursing and residential homes have expanded from 220,000 places to 480,000 places in England. ${ }^{23}$ These represent a close substitute for a service formerly provided by the NHS and by social services. We lack direct national data on their quality of service, but there are some significant indicators:

The accommodation standards have improved so that by 1997, 60 per cent of clients had single rooms and many had en suite bathrooms.

The market for "self-pay" accommodation had developed so that, by 1998, some 20 per cent of residents were paying for themselves in whole or part. These self-pay residents share homes under the same standards as residents funded by the public sector.

There are constraints on the public funding of places: but there is no waiting for places once funding is available and in most areas the client has choice. Private nursing and residential homes are subject to independent inspection, including unannounced visits. Public sector homes and NHS places have not in the past been subject to independent review.

In summary, it is highly likely that pluralism is providing more choice and a better average standard than the NHS and social services could have done on their own. ${ }^{24}$ The private framework, with a variety of providers and local choice, provides for more continuous scrutiny and checks on abuse than the former public sector monopoly has done. Indeed, private sector investment is now making it possible for the new Care Standards Commission to set new and ambitious standards.

In addition, the funders have derived certain practical advantages. They have been able to "buy" places in nursing homes at under half the weekly 
cost of places in long-stay NHS hospitals $(£ 350$ a week against $£ 800) .{ }^{23}$ These places have been available flexibly and any under-occupation has been at the risk of the providers. They have reduced "bed blocking" of acute beds in NHS hospitals, which was becoming a very serious problem in the late 1970s.

\section{Home care services}

Home care services provide support at home with day-to-day living for people who might otherwise have to move into residential and nursing homes. Since 1993, social services have had to invite tenders for such services. The result has been the development of a new industry in privately provided home care.

The number of hours from private and voluntary providers has risen from 32,000 (3 per cent of the total) to $1 \mathrm{~m}$ (40 per cent) in $1998 .^{23}$ These hours cost less than public sector home help hours ( $f 7$ an hour compared to $£ 12$ ): and by some indicators the private supply offers higher quality, with the help being more available early in the morning and late in the evening, and being guaranteed against sickness and holidays.

As a result of the expansion of private services, many frail elderly people have received a service that would simply not have previously been available. If all hours had been available at the private sector cost of $£ 7$ an hour, some one million more hours would have been available for the same budget. This expansion also led to an increasing self-pay market as the hours became more affordable and accessible.

\section{Summing up: gains to pluralism}

The general advantages from pluralism include speed: the external suppliers work to contracts which set times and quality standards. Failure to reach these standards is the risk taken by the supplier. On past evidence the effect of competition has been to reduce prices and costs and to enlarge access to international capital and expertise. The funders are not limited to the capital available from the British public sector. The Private Finance Initiative (PFI) schemes currently under way in the UK have shown how these advantages can be used to produce a much larger and better value hospital building programme. ${ }^{19}$ The current programme of 38 hospitals would have been far beyond the design and build capacity of the UK public sector on its own, which had a long record of delays and cost overruns in projects.

There are even more advantages from pluralism in giving choice to users and giving pressures to higher quality. A public sector monopoly has to provide a similar service to all users or run into criticism for discrimination or postcode rationing. With a range of providers it is easier to have different models and locations of service which can offer more choice to users. It is also more feasible to monitor standards where there are a number of smaller projects and for them to provide the investment required to increase quality. Once a public sector monopoly has a maintenance or performance backlog it is usually costly and difficult to lever standards back up. Public sector monopoly may perform satisfactorily for a time, but the very size of the organisation and the problems of control and management represent a larger risk in terms of quality. It could be argued that the public sector could be reformed so as to produce decentralised, autonomous units that would in effect compete against one another. But if this were to be done, then it might be just as sensible to move to the real gains from competition. The NHS would be much more likely to deliver sustained improvements in services if there were choices of supplier. A 70-30 NHS-with at least 30 per cent of services provided by alternative suppliers-would create better conditions for innovation and give suppliers an incentive to increase market share through expanding output and reducing costs.

Pluralism will also make it more possible to explore trade-offs and the positive agenda for marginal change. Public sector monopoly is likely to be inflexible and to produce similar patterns of service. Where there are economic incentives it is possible to vary supply in order to relate to different patterns of utility. Pluralism allows greater movement towards economic efficiency with variations both in preferences and in production. Active management by funders is needed to ensure quality standards. ${ }^{25}$ Pluralism is not a miracle cure, but it does point towards a more positive local process for improving care.

There will still be issues of choice and rationing but, with greater use of pluralism, these will be more limited to services that are inherently high cost. Society will still face choices about whether to treat actively all low-weight premature babies or whether people in their late 80 s should be able to get kidney transplants. There will still be problems in deciding how to use scarce resources in funds and professional skills, but there will be fewer problems in the rationing of services that can be produced at lower cost through pluralism. In summary, pluralism has some highly specific advantages: access to international capital, greater flexibility in teamwork, production on an optimal scale, specialisation, and speed in getting new projects under way. It is particularly important now that the NHS could draw on expertise in information technology (IT) and other areas of the new service economy. Pluralism can raise staff motivation, make it more possible to develop a focus on customer needs and create greater pressure to improve quality and standards.

\section{Conclusions: a rebalanced agenda}

The efficiency agenda needs to be developed alongside the equity agenda. The practical implication of the two agendas can be illustrated in relation to services for elderly people. Health economists have become associated with the view that rationing is the key area for concern in the future. Thus they 
have developed the fair innings approach, which would mean that older people were further back in the queue for services. ${ }^{26}$ The efficiency agenda would point towards encouraging cost-effective programmes in improving services for early intervention and home-based care that could improve long term outcomes and access to services. Economists have contributed to myths of demographic time-bombs and of the extraordinary costs of ageing and have given little encouragement to the development of new programmes.

The efficiency agenda can also be illustrated in relation to the issues of renal dialysis. Much research has been carried out on the rationing dilemmas posed, but there has been very little work in increasing the efficiency of dialysis so as to improve access for patients via more intensive throughput using the existing plant. ${ }^{27} \mathrm{~A}$ few centres in the UK have introduced personal care programmes that set for each individual the amount of dialysis time required to meet a certain standard. Most units deliver a standard amount of dialysisusually a four-hour session. With personal programmes it is possible to treat 30 per cent more patients with the existing dialysis stations. Yet these and other efficiency increasing changes have hardly appeared on the agenda of health economists, who remain overwhelmingly concerned with issues of equity.

In summary, health economics has failed to explore options for harnessing the dynamic forces of choices and competition to improving health services and developing low-cost effective programmes. Instead health services are moving into a future of rising costs, provider power and painful decisions on rationing. The focus on aspirations rather than performance has in fact increased the ethical dilemmas of health services by cutting them off from cost-reducing innovation. An ethics of results would have led to greater flexibility and pragmatism about the means required to achieve them. We should seek the process of health care service supply and development that maximises the delivery of high quality, lower cost user relevant services.

\section{Acknowledgement}

I am most grateful to Richard Ashcroft for comments on an earlier draft of this paper.

Nick Bosanquet, BA, Msc, is Professor of Health Policy, Department of Primary Care and General Practice,
Imperial College School of Medicine, Imperial College, University of London.

\section{References}

1 Donaldson C. Why a National Health Service? The economic rationale. London: IPPR, 1998.

2 Bosanquet H. The strength of the people. London: Macmillan, 1902.

3 Beveridge Sir W. Social insurance and allied services. London: HMSO, 1942. (Cmnd 6404)

4 Bradshaw JS. A taxonomy of social need. In: McLachlan G, ed. Problems and progress in medical care. Essays on current research. Oxford: OUP, 1972 .

5 Culyer AJ. Need and the National Health Service. Oxford: Martin Robertson, 1976.

6 Williams A. 'Need'-an economic exegesis. In: Culyer A, Wright 6 Williams A. 'Need'-an economic exegesis. In: Culyer A, Wright
KG, eds. Economic aspects of health services. Oxford: Martin Robertson, 1978: 32-45.

7 See reference 5: 16

8 Culyer AJ, Wagstaff A. Equity and equality in health and health care. Fournal of Health Economics 1993;12:431-57.

9 Culyer AJ. Equality of what in health policy? Conflicts between the contenders [discussion paper 142]. Centre for Health Economics, University of York, 1995 .

10 Mooney G, Hall J, Donaldson C, Gerard K. Utilisation as a measure of equity: weighing heat? Fournal of Health Economics 1991;10:475-80.

11 Mooney G, Hall J, Donaldson C, Gerard K. Reweighing heat: response to Culyer, van Doorslaer and Wagstaff. Fournal of Health Economics 1992;11:199-205.

12 Department of Health. National Service framework: coronary heart disease. London: DoH, 2000.

13 Redwood H. Why ration health care? London: Civitas, 2000.

14 Porter M. The competitive advantage of nations. London: Macmillan, 1990.

15 The World Health Organization. Health systems: improving performance. Geneva: World Health Organization, 2000. [WHO report 2000]

16 Saltman RB, Figueras J. European health care reform. Geneva: World Health Organization, 1997.

17 Morris P. Put away. London: Routledge and Kegan Paul, 1969.

18 Bosanquet N. A successful National Health Service. London: Adam Smith Institute 1999.

19 House of Commons Health Committee. Public expenditure on health and personal social services. London: The Stationery health and personal sociat

20 Ritchie J, Keegan J, Bosanquet N. Housing for mentally ill and mentally handicapped people. London: HMSO, 1983.

mentally handicapped people. London: HMSO, 1983.
Townsend P. The last refuge. London: Routledge, 1962.

21 Townsend P. The last refuge. London: Routledge, 1962 . Standing Nursing Advisory Committee. Caring for older people:
a nursing priority. London: DoH, 2001. Robb B. Sans everything. London: Nelson, 1967.

23 Laing and Buisson. Care of elderly people. Market survey 2000. London: Laing and Buisson, 2000.

24 Royal Commission on long term care. With respect to old age. London: The Stationery Office, 1999. (Cmnd 4172)

25 Knapp M, Hallam A, Beecham J, Baines B. Private, voluntary or public? Comparative cost-effectiveness in community mental health care. Policy and Politics 2000;27:25-41.

26 Williams A. Intergenerational equity: an exploration of the "fair innings' argument. Health Economics 1997;6.:117-32.

27 Bosanquet N. An economic perspective on renal services. British fournal of Renal Medicine 1997;2:18-21. 